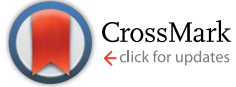

Cite this: RSC Adv., 2016, 6, 105940

Received 30th August 2016 Accepted 26th October 2016

DOI: 10.1039/c6ra21691a

www.rsc.org/advances

\section{Monodisperse AgPd alloy nanoparticles as a highly active catalyst towards the methanolysis of ammonia borane for hydrogen generation}

\author{
Daohua Sun, ${ }^{*}$ Pengyao Li, Bin Yang, Yan Xu, Jiale Huang and Qingbiao Li \\ Monodisperse AgPd nanoparticles (NPs) were successfully synthesized by coreducing silver nitrate and \\ palladium chloride in the presence of oleylamine. Characterization techniques such as transmission \\ electron microscopy, energy-dispersive X-ray spectroscopy, and X-ray diffraction were employed to \\ verify the alloy nature of the obtained NPs. These AgPd NPs, supported on carbon, were found to be \\ active catalysts for the generation of hydrogen from the methanolysis of ammonia borane at room \\ temperature. The catalytic activity depended on the alloy composition, and the $\mathrm{Ag}_{30} \mathrm{Pd}_{70} \mathrm{NPs}$ displayed \\ the greatest activity among the tested catalysts, with a very high total turnover frequency value of 366.4 \\ $\mathrm{min}^{-1}$ and activation energy of $37.5 \mathrm{~kJ} \mathrm{~mol}^{-1}$. In a reusability test, the $\mathrm{Ag}_{30} \mathrm{Pd}_{70} / \mathrm{C}$ catalyst retained $67 \%$ \\ of its initial activity and $100 \%$ conversion after eight cycles.
}

\section{Introduction}

Storage and transport of hydrogen are the widely accepted technological barriers to the development of the so-called hydrogen economy. ${ }^{1}$ As the lightest element in the periodic table, hydrogen in the gas form is extremely difficult to store. Considering economically viable and safe practices, efforts have been directed towards the development of chemical hydrides as a potential onboard storage form of hydrogen., Ammonia borane (AB) has been considered to be the most promising candidate among the chemical hydrides. ${ }^{4,5}$ This molecule is stable in the solid state at ambient temperatures and has shown an impressive gravimetric capacity of $19.6 \mathrm{wt} \% \mathrm{H}_{2}$, potentially capable of meeting the 2015 target of the U.S. Department of Energy ( $9 \mathrm{wt} \%$ hydrogen for a material to be practically applicable).$^{6,7}$ Hydrogen stored in $\mathrm{AB}$ can be produced and obtained by pure thermal decomposition, hydrolysis and methanolysis using a suitable catalyst. Considering the mild reaction conditions and favorable kinetics, solvolysis is preferred..$^{\mathbf{7}}$ The methanolysis or hydrolysis of AB can release 3.0 equivalents of hydrogen in the presence of a suitable catalyst. However, the hydrolysis of $\mathrm{AB}$ in concentrated solutions can cause liberation of ammonia gas, which can poison Pt-based fuel cells, and the hydrolysis product ammonium metaborate is difficult to recycle, which can pose enormous challenges to practical applications. ${ }^{\mathbf{9}, 10}$ In a previous study by Ramachandran, when methanol was used instead of water, the catalytic methanolysis of $\mathrm{AB}$ yielded hydrogen gas without ammonia evolution,

Department of Chemical and Biochemical Engineering, College of Chemistry and Chemical Engineering, National Laboratory for Green Chemical Productions of Alcohols, Ethers and Esters, Xiamen University, Xiamen, 361005, P. R. China. E-mail: sdaohua@xmu.edu.cn; Fax: +86 592 2184822; Tel: +86 5922183088 and yielded the recyclable methanolysis product ammonium tetramethaoxyborate. ${ }^{6}$ In addition, the methanolysis reaction can even be initiated at temperatures below $0{ }^{\circ} \mathrm{C}$ through use of a suitable catalyst, which satisfies applications in cold weather. ${ }^{11}$

Since methanolysis of $\mathrm{AB}$ can achieve a complete release of hydrogen in the presence of a suitable catalyst, finding the best catalyst for this process is very important. Heterogeneous catalysts were the first ones to be tested for the methanolysis of AB. $\mathrm{RuCl}_{3}$ and $\mathrm{RhCl}_{3}$ have been shown to exhibit excellent catalytic activity, but they are difficult to isolate and they display low stability, features that seriously restrict their practical application. ${ }^{6} \mathrm{Cu} @ \mathrm{Cu}_{2} \mathrm{O}, \mathrm{Cu}_{2} \mathrm{O},{ }^{12} \mathrm{Co}-\mathrm{Co}_{2} \mathrm{~B}, \mathrm{Ni}-\mathrm{Ni}_{2} \mathrm{~B}, \mathrm{Co}-\mathrm{Ni}-\mathrm{B},{ }^{13}$ and $\mathrm{Cu}-\mathrm{Cu}_{2} \mathrm{O}-\mathrm{CuO} / \mathrm{C}^{14}$ are cheaper transition metal-based catalysts, but suffer from low activity. The performance of the catalyst in the methanolysis of $\mathrm{AB}$ appears to depend on the identity of the metal. Thus, recent studies have been directed toward bimetallic alloy nanoparticles (NPs), as their catalytic properties have been found to be superior to those of either component metal alone due to synergistic effects. Our previous studies have also indicated monodisperse CoPd NPs ${ }^{15}$ and CuPd $\mathrm{NPs}^{16}$ to be more active than Pd-rich NPs in catalyzing the AB methanolysis reaction, with total turnover frequency (TOF) values of 27.7 and $53.2 \mathrm{~min}^{-1}$, respectively, having been attained.

Despite the significant progress made in the synthesis of bimetallic alloy NPs, ${ }^{17,18}$ size-controlled fabrication of nanostructures has become one of the most important and challenging aspects of modern nanotechnology. In the widely used method, the metal NPs are generated from the reduction of metal ions in solution in the presence of a stabilizer or supporting materials. ${ }^{19}$ To obtain uniformly sized, shapecontrolled, and highly dispersed monodisperse NPs, "hot 
injection" techniques, which utilize homogeneous nucleation to synthesize monodisperse nanocrystals in organic solutions, are commonly used. For example, when using this technique, Sun $^{20}$ prepared CoPd NPs with diameters of 5-12 nm and with a standard deviation of the diameter of less than $7 \%$. Hyeon ${ }^{21}$ even succeeded in the incremental $1 \mathrm{~nm}$ size controlled synthesis of iron oxide NPs ranging from 6 to $13 \mathrm{~nm}$. To allow precise control over size and monodispersity, capping agents such as oleic acid and organic metal salt precursor (e.g., acetylacetonate) have usually been employed. ${ }^{2-24}$ These agents, however, increase the costs of the catalytic process. Therefore, it is of crucial importance to develop rational cost-effective approaches to synthesize monodisperse alloy NPs.

Herein, we report the synthesis of monodisperse AgPd alloy NPs from inorganic salt silver(I) nitrate and palladium(II) chloride in oleylamine, and the evaluation of their performance in catalyzing the methanolysis of $\mathrm{AB}$ at ambient conditions. We demonstrated that the activity of these AgPd NPs can be enhanced by properly controlling the $\mathrm{Ag} / \mathrm{Pd}$ molar ratio. In addition, these AgPd NPs showed a very high catalytic activity and prolonged lifetime.

\section{Experimental}

\subsection{Chemicals}

$\mathrm{AgNO}_{3}, \mathrm{PdCl}_{2}$, isopropanol, hexane and methanol were of analytical levels and used as received without any further purification. The borane-ammonia complex (90\%) and oleylamine (80-90\%) were purchased from Sigma-Aldrich and Aladdin, respectively. All pieces of glassware were washed several times with aqua regia and ordinary distilled water.

\subsection{Preparation of AgPd NPs}

Typically, under the protection of a constant nitrogen flow, $0.2 \mathrm{mmol} \mathrm{AgNO}$ and $0.2 \mathrm{mmol} \mathrm{PdCl}_{2}$ were added into a fournecked flask with $15 \mathrm{~mL}$ of oleylamine. The mixture was heated to $110^{\circ} \mathrm{C}$ gradually and kept at this temperature for $0.5 \mathrm{~h}$ in order to remove oxygen and moisture from the flask, and then the solution was heated to $210{ }^{\circ} \mathrm{C}$ at a heating rate of $4{ }^{\circ} \mathrm{C}$ $\min ^{-1}$ and maintained at this temperature for $1 \mathrm{~h}$ before being cooled to room temperature. Afterwards, the mixture and $40 \mathrm{~mL}$ of isopropanol were transferred to centrifuge tubes, and the product was separated by centrifugation at $10000 \mathrm{rpm}$ for $10 \mathrm{~min}$. Finally, the product was dispersed in hexane.

For comparison, Ag NPs and Pd NPs were also, separately, synthesized and obtained. The Ag NPs were prepared by carrying out thermal decomposition of $\mathrm{AgNO}_{3}$ in the presence of oleylamine. The Pd NPs were prepared by carrying out thermal decomposition of $\mathrm{PdCl}_{2}$ in oleylamine. The procedures used to synthesize the Ag NPs and Pd NPs were similar to that used to synthesize AgPd NPs.

\subsection{Preparation of the catalyst}

Typically, accurately weighed $10 \mathrm{mg}$ of AgPd nanoparticles were redispersed in $5 \mathrm{~mL}$ hexane and $5 \mathrm{~mL}$ acetone in a vial with a volume of $20.0 \mathrm{~mL}$, and then a mass of $30 \mathrm{mg}$ of Ketjen carbon $\left(\sim 750 \mathrm{~m}^{2} \mathrm{~g}^{-1}\right)$ was added. The resulting mixture was sonicated for $2 \mathrm{~h}$ to ensure that the nanoparticles were completely loaded onto the support. Next, the black solid residue AgPd/C catalyst was obtained after the hexane and acetone were vaporized as a result of a constant flow of nitrogen.

\subsection{Evaluation of the catalytic activity}

To evaluate the catalytic activity of the $\mathrm{AgPd} / \mathrm{C}$ catalyst for methanolysis of $\mathrm{AB}$, the classic water-displacement method involving determining the rate of hydrogen generation was performed. ${ }^{15}$ Typically, a volume of $10 \mathrm{~mL}$ of a methanol suspension of the AgPd/C catalyst was transferred into a reaction flask $(25 \mathrm{~mL})$ containing a Teflon-coated stir bar placed on a magnetic stirrer. The reaction temperature was maintained at $25{ }^{\circ} \mathrm{C}$ using a constant temperature bath during the process, and the reaction flask was connected to a burette filled up with water to measure the volume of hydrogen. Weighed $\mathrm{AB}$ was then added into the reaction flask quickly with stirring at a rate of $800 \mathrm{rpm}$. The volume of hydrogen generated from methanolysis of $\mathrm{AB}$ in the flask was monitored and measured by recording the displacement of the water level at various intervals of time. The reaction was considered to be complete when the generation of more gas was no longer observed.

\subsection{Characterizations}

Samples used for TEM and HRTEM analyses were prepared in advance by sonicating AgPd in hexane at a proper concentration and then depositing a drop of the resulting dispersion on a carbon-coated copper grid. The morphologies of the various types of NPs were visualized by using a TEM instrument operating at $300 \mathrm{kV}$, and an elemental analysis of the AgPd NPs was performed by carrying out an energy-dispersive X-ray spectroscopy (EDX) experiment. The dried and powdered samples were analyzed via X-ray diffraction (XRD) by using an X-ray diffractometer (Phillips, Netherlands) with $\mathrm{Cu} \mathrm{K} \alpha$ radiation $(40 \mathrm{kV}, 30$ $\mathrm{mA})$. The composition and metallic content of the NPs were determined by performing inductively coupled plasma mass spectrometry (ICP-MS) (Agilent 7700x). The dried NPs were dissolved in $\mathrm{HNO}_{3}$ to assure the complete dissolution of the metal into the acid, and the obtained solution was then diluted with $2 \% \mathrm{HNO}_{3}$. X-ray photoelectron spectroscopy (XPS) measurements were taken with an X-ray photoelectric spectrophotometer, and all binding energies were referenced to the $\mathrm{C}$ 1s peak, at $284.8 \mathrm{eV}$.

\section{Results and discussion}

\subsection{Synthesis and characterization of the monodisperse AgPd NPs}

Zhang has reported the synthesis of AgPd alloy NPs with dimensions of $2.2 \mathrm{~nm}$ by coreducing $\mathrm{Ag}(\mathrm{Ac})$ and $\mathrm{Pd}(\mathrm{acac})_{2}$ in oleylamine, oleic acid and 1-octadecene at $180{ }^{\circ} \mathrm{C} .{ }^{22} \mathrm{We}$ replaced the above precursors with inorganic metal salts to yield a procedure that is more cost-effective but for which obtaining monodisperse nanoparticles is more challenging. Specifically, AgPd NPs were synthesized from $\mathrm{AgNO}_{3}$ and $\mathrm{PdCl}_{2}$ in 
oleylamine at $220{ }^{\circ} \mathrm{C}$ under the protection of a constant flow of nitrogen. The morphology and structure of the as-synthesized AgPd NPs were observed by performing TEM. For a molar ratio of $\mathrm{Ag}$ to $\mathrm{Pd}$ of about $1: 1$, the composition of the assynthesized NPs was determined using ICP-MS to be $\mathrm{Ag}_{36} \mathrm{Pd}_{64}$.
The as-synthesized NPs were observed to be spherical, with a mean diameter of $6.2 \mathrm{~nm}$ (Fig. 1(a)). These NPs were monodisperse, with a standard deviation of $\sim 5 \%$. STEM-EDX images of the $\mathrm{Ag}_{36} \mathrm{Pd}_{64}$ NPs are shown in Fig. 1(b)-(e). Close inspection of several as-synthesized NPs suggested the Ag (Fig. 1(d)) and Pd
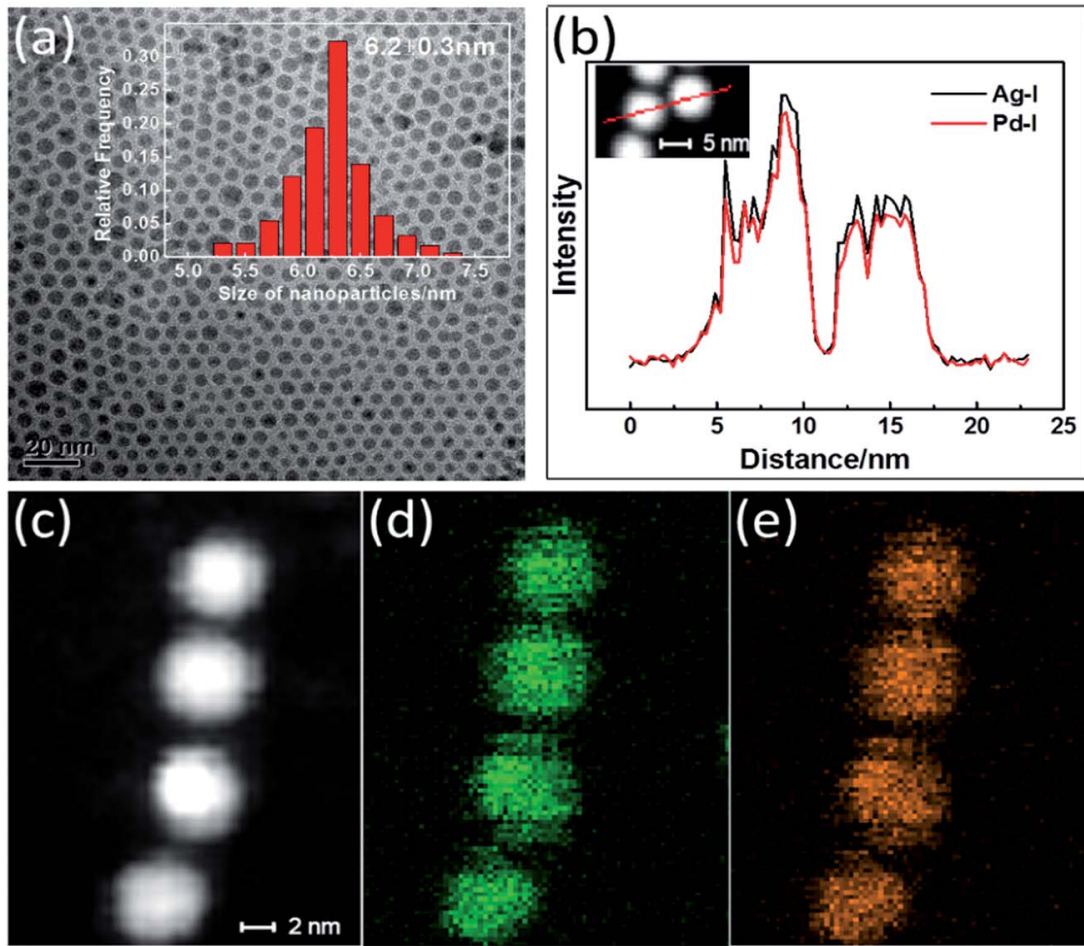

Fig. 1 (a) TEM image and size histogram (inset) of the AgPd NPs. (b) Distributions of Ag and Pd components along the cross-sectional line profiles of two AgPd NPs. (c) High-magnification STEM image of AgPd NPs. (d and e) EDX elemental maps for Ag (d, green) and Pd (e, yellow) concentrations within four individual AgPd NPs.
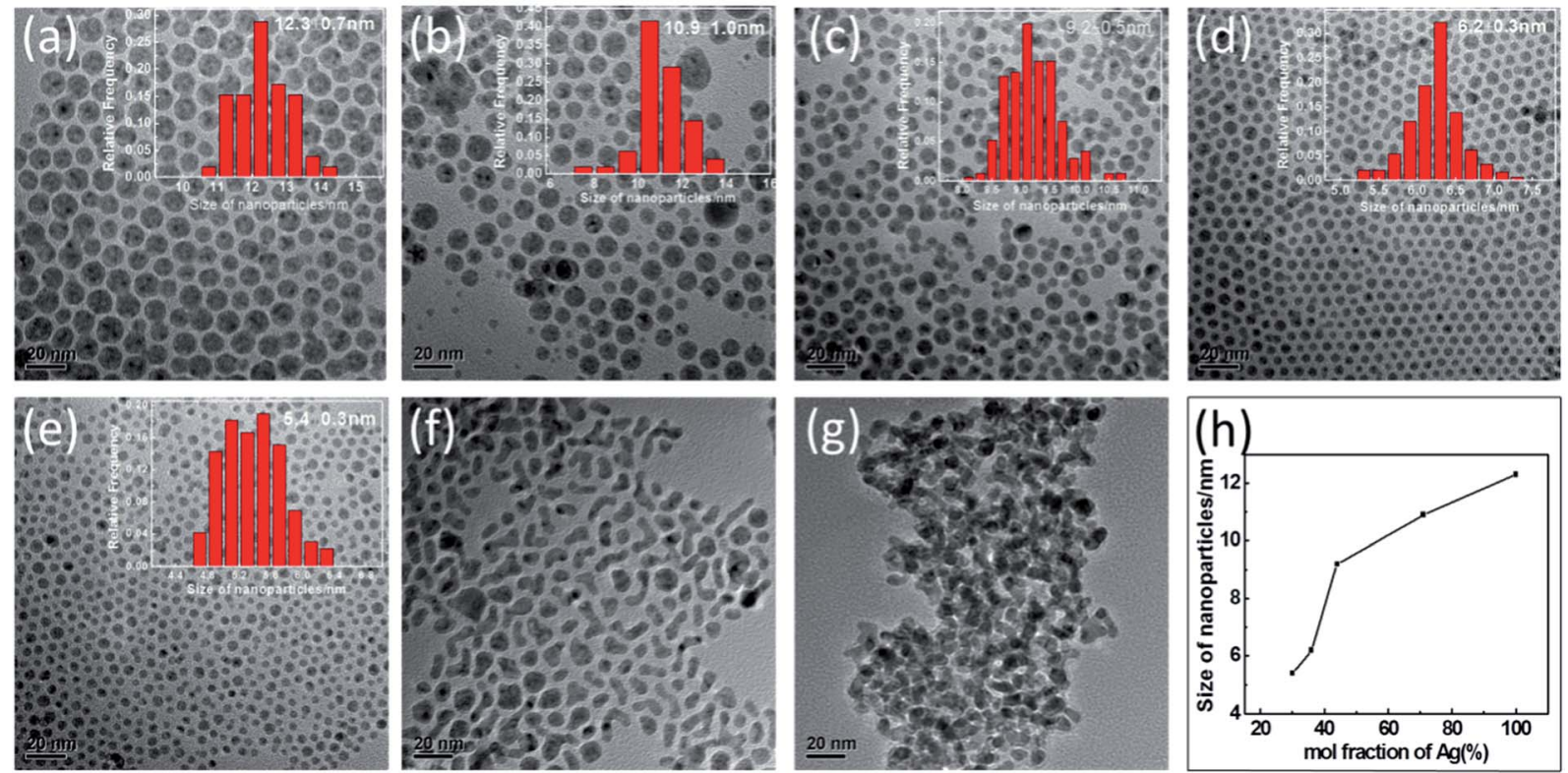

Fig. 2 Representative TEM images of (a) Ag, (b) $\mathrm{Ag}_{71} \mathrm{Pd}_{29}$, (c) $\mathrm{Ag}_{44} \mathrm{Pd}_{56}$, (d) $\mathrm{Ag}_{36} \mathrm{Pd}_{64}$, (e) $\mathrm{Ag}_{30} \mathrm{Pd}_{70}$, (f) $\mathrm{Ag}_{12} \mathrm{Pd}_{88}$ and (g) Pd NPs. (h) Plot of $\mathrm{AgPd} \mathrm{NPs}$ size versus mole fraction of $\mathrm{Ag}$. 
(Fig. 1(e)) atoms to be evenly distributed throughout the NP. Moreover, EDX elemental line scanning of two NPs (Fig. 1(b)) also verified the presence of the alloy structure in these NPs.

The composition and size of AgPd bimetallic NPs could be facilely controlled by changing the ratio of $\mathrm{AgNO}_{3}$ to $\mathrm{PdCl}_{2}$. In our study, the total amounts of $\mathrm{AgNO}_{3}$ and $\mathrm{PdCl}_{2}$ were each set at $0.4 \mathrm{mmol}$, and ICP analyses indicated that as-synthesized NPs with the formulas $\mathrm{Ag}_{71} \mathrm{Pd}_{29}, \mathrm{Ag}_{44} \mathrm{Pd}_{56}, \mathrm{Ag}_{36} \mathrm{Pd}_{64}, \mathrm{Ag}_{30} \mathrm{Pd}_{70}$ and $\mathrm{Ag}_{12} \mathrm{Pd}_{88}$ were obtained when using the molar ratios of $\mathrm{AgNO}_{3}$ to $\mathrm{PdCl}_{2}$ of $9: 1,7: 3,5: 5,3: 7$, and $1: 9$, respectively. The TEM images of each of the above five NPs are shown in Fig. 2(b)-(f), with an image of the Ag NPs shown in Fig. 2(a) and that of the Pd NPs in Fig. 2(g). All of the as-synthesized NPs were observed to be spherical in shape and well-dispersed, except for the $\mathrm{Ag}_{12} \mathrm{Pd}_{88}$ and Pd NPs. The results may be attributed to the smaller particles more easily agglomerating during the synthetic process. As shown in Fig. 2(h), when the mole fraction of $\mathrm{Ag}$ was increased from $30 \%$ to $100 \%$, the dimensions of the resulting particle increased on average from $5.4 \mathrm{~nm}$ to $12.3 \mathrm{~nm}$. The influence of the molar ratio of the metals on the size of the bimetallic alloy NPs has also been reported in earlier studies. $^{25,26}$ The dependence of the size of the alloy NPs on the composition has been indicated to be related to the collision energy, sticking coefficient, rate of nucleation and growth. ${ }^{27}$

XRD patterns of the monometallic and bimetallic NPs are shown in Fig. 3(b). Each pattern exhibited several diffraction peaks, which can be indexed to the (111), (200), (220), (311) and (222) planes of the fcc structure of $\mathrm{Ag}$ and Pd, representing five diffraction rings in the selected area electron diffraction (SAED) pattern (Fig. 3(a)). Fig. 3(c) shows a plot of the diffraction angle versus the Pd molar fraction. All of these XRD peaks gradually shifted to larger angles as the Pd content was increased. As shown in the inset of Fig. 3(c), an intense peak resulted from each of the AgPd NPs produced using $\mathrm{AgNO}_{3}$ to $\mathrm{PdCl}_{2}$ ratios of
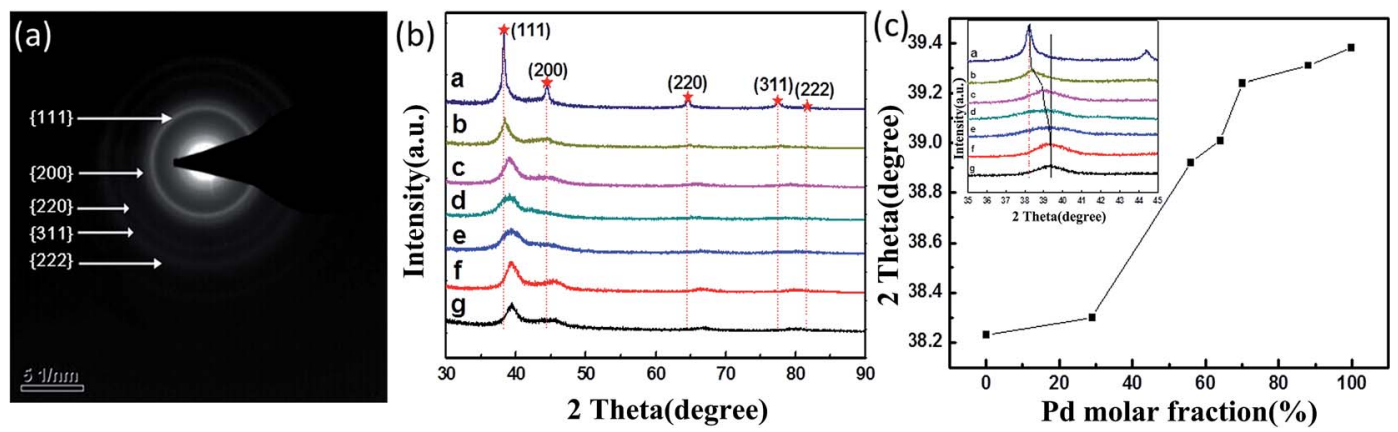

Fig. 3 (a) SAED image from $\mathrm{Ag}_{36} \mathrm{Pd}_{64}$ nanoparticles (NPs). (b) XRD patterns and (c) (111) diffraction peak positions of the (a) $\mathrm{Ag}$, (b) $\mathrm{Ag}_{71} \mathrm{Pd}_{29}$, (c) $\mathrm{Ag}_{44} \mathrm{Pd}_{56},(\mathrm{~d}) \mathrm{Ag}_{36} \mathrm{Pd}_{64}$, (e) $\mathrm{Ag}_{30} \mathrm{Pd}_{70}$, (f) $\mathrm{Ag}_{12} \mathrm{Pd}_{88}$ and (g) Pd NPs.
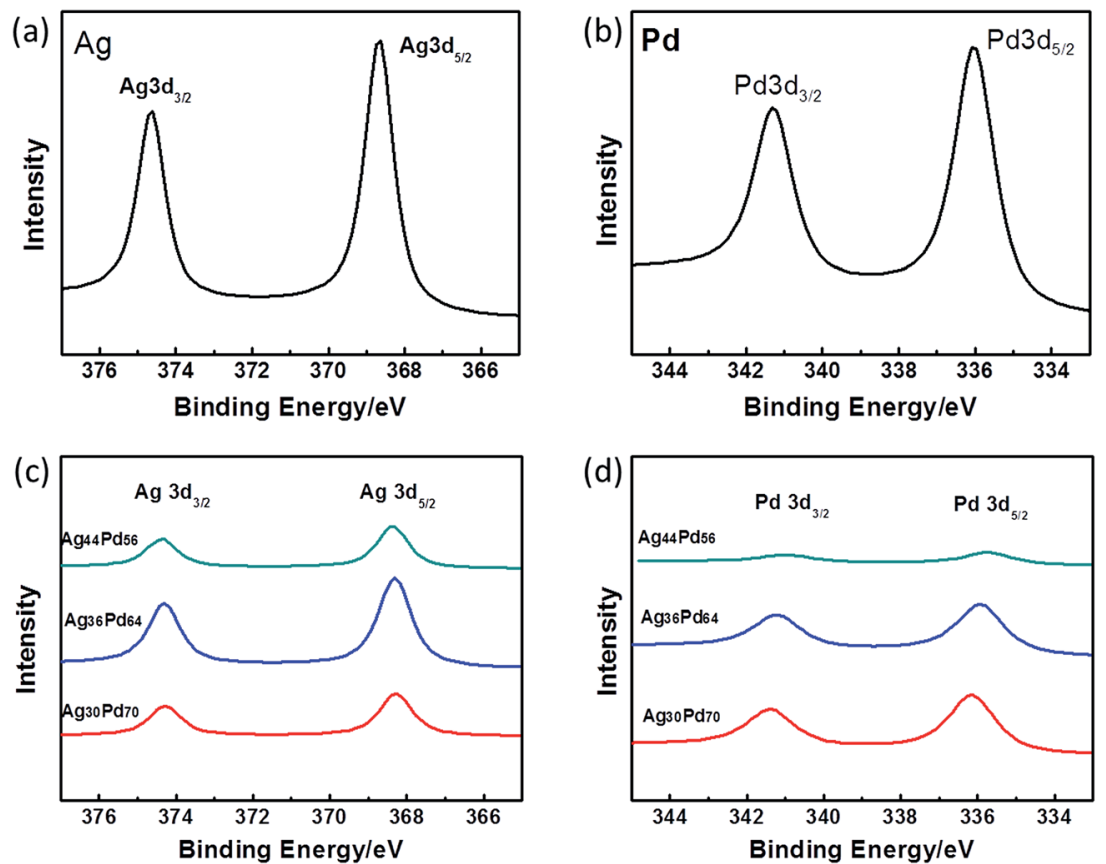

Fig. 4 X-ray photoelectron spectroscopy (XPS) patterns showing the (a) Ag 3d region for the Ag NPs, (b) Pd 3d region for the Pd NPs, (c) Ag 3d and (d) Pd 3d regions for the AgPd alloy NPs. 
Table 1 X-ray photoelectron spectroscopy (XPS) peak positions of Ag, Pd and AgPd NPs

\begin{tabular}{|c|c|c|c|c|}
\hline \multirow[b]{3}{*}{ NPs } & \multicolumn{4}{|c|}{ Binding energy (eV) } \\
\hline & \multicolumn{2}{|l|}{$\mathrm{Ag}$} & \multicolumn{2}{|l|}{ Pd } \\
\hline & $3 d_{5 / 2}$ & $3 d_{3 / 2}$ & $3 d_{5 / 2}$ & $3 d_{3 / 2}$ \\
\hline $\mathrm{Ag}$ & 368.66 & 374.65 & & \\
\hline $\mathrm{Ag}_{44} \mathrm{Pd}_{56}$ & 368.36 & 374.37 & 340.96 & 335.69 \\
\hline $\mathrm{Ag}_{36} \mathrm{Pd}_{64}$ & 368.29 & 374.29 & 341.20 & 335.91 \\
\hline $\mathrm{Ag}_{30} \mathrm{Pd}_{70}$ & 368.28 & 374.27 & 341.42 & 336.12 \\
\hline Pd & & & 341.28 & 336.00 \\
\hline
\end{tabular}

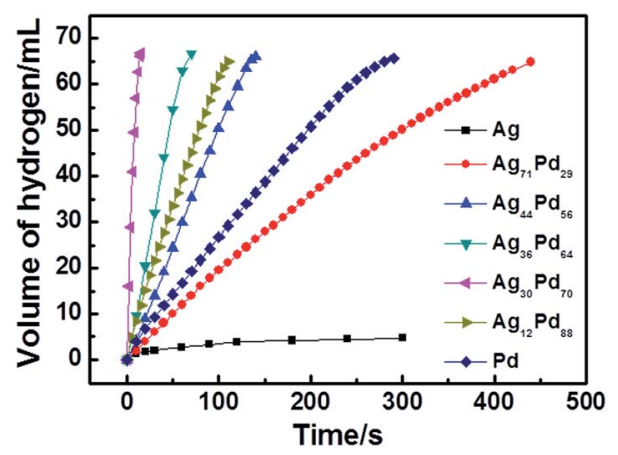

Fig. 5 Plots of reaction time versus volume of hydrogen released from the methanolysis of $A B$ catalyzed by $A g P d / C$ catalysts with different compositions (10 $\mathrm{mg} \mathrm{NPs},[\mathrm{AB}]=100 \mathrm{mM}, T=25 \pm 1^{\circ} \mathrm{C}$ ).

$9: 1,7: 3,5: 5,3: 7,1: 9$, respectively. The curves in this figure indicated that the positions of the (111) diffraction peaks from the AgPd NPs were indeed between that from a pure Ag crystal at $38.23^{\circ}$ and that from a pure Pd crystal at $39.23^{\circ}$. These results further confirmed the alloy nature of the products synthesized from the various initial molar ratios of $\mathrm{AgNO}_{3}$ to $\mathrm{PdCl}_{2}$.

The $\mathrm{Ag} 3 \mathrm{~d}$ and $\mathrm{Pd} 3 \mathrm{~d}$ regions of the XPS spectra of three representative AgPd alloy NPs are shown in Fig. 4(c) and (d), respectively. For comparison, Fig. 4(a) and (b) show the XPS spectra of the Ag 3d and Pd 3d regions of monometallic Ag NPs and Pd NPs, respectively. The differences ( $\Delta$ values) between the positions of the $3 \mathrm{~d}_{5 / 2}$ and $3 \mathrm{~d}_{3 / 2}$ peaks of $\mathrm{Ag}$ were observed to be
$6.0 \mathrm{eV}$, and the differences between the positions of the $3 \mathrm{~d}_{5 / 2}$ and $3 \mathrm{~d}_{3 / 2}$ peaks of Pd were observed to be $5.3 \mathrm{eV}$. These values were the same as the reported values for zero-valent $\mathrm{Ag}$ and $\mathrm{Pd}$, respectively. ${ }^{28,29}$ Hence, $\mathrm{Ag}$ and $\mathrm{Pd}$ atoms existed in the zerovalent state in all of the prepared alloy samples. The positions of the XPS peaks are listed in Table 1 for further reference. The binding energy of $\mathrm{Ag} 3 \mathrm{~d}$ was clearly shifted to lower energy and the binding energy of Pd $3 d$ shifted to higher energy when the Pd content was increased, indicating that Ag and Pd formed an alloy cluster. ${ }^{30}$ The formation of interfacial metal-metal bonds for a bimetallic alloy can produce large perturbations to the Hamiltonian, binding energy density, and hence the catalytic properties. ${ }^{31}$ Sun has mentioned that the polarization of AgPd shifts the valence density of state to generate excessive electrons, which makes the AgPd alloy serve as a charge donor in the catalytic reaction. $^{32}$

\subsection{Methanolysis of AB catalyzed by monodisperse AgPd NPs}

The as-synthesized NPs supported on Ketjen carbon acted as catalysts for the generation of hydrogen from the methanolysis of the AB solution. As shown in Fig. 5, pure Ag NPs, pure Pd NPs and 5 compositions of AgPd NPs supported on Ketjen carbon exhibited different levels of catalytic activity for the methanolysis of $\mathrm{AB}$. Interestingly, among the tested catalysts, $\mathrm{Ag}_{30} \mathrm{Pd}_{70} / \mathrm{C}$ NPs displayed the highest catalytic activity with a completion time of $15 \mathrm{~s}$ for $100 \mathrm{mM} \mathrm{AB}$, obviously better than those of pure Pd NPs and Ag NPs, which indicated the existence of a synergistic effect between the Ag and Pd. The metal content of the oleylamine-coated $\mathrm{Ag}_{30} \mathrm{Pd}_{70}$ was determined, using ICP$\mathrm{AES}$, to be $34.6 \mathrm{wt} \%$. The catalytic activity of $\mathrm{Ag}_{30} \mathrm{Pd}_{70} / \mathrm{C}$ for the methanolysis of $\mathrm{AB}$ was also assessed by determining its TOF, which was found to be $366.4 \mathrm{~mol}$ of $\mathrm{H}_{2}$ (mol of catalyst $\mathrm{min})^{-1}$. The very high activity of $\mathrm{Ag}_{30} \mathrm{Pd}_{70} \mathrm{NPs}$ probably resulted from their small dimensions and regular shapes.

\subsection{Methanolysis kinetics of the $\mathrm{Ag}_{30} \mathrm{Pd}_{70} / \mathrm{C}$ catalyst}

As the $\mathrm{Ag}_{30} \mathrm{Pd}_{70} / \mathrm{C}$ catalyst exhibited the highest activity, we chose it for further study of its kinetics. First, the methanolysis reaction was carried out using various dosages of the $\mathrm{Ag}_{30} \mathrm{Pd}_{70}$ NPs, specifically at $0.5 \mathrm{mg}, 2 \mathrm{mg}, 5 \mathrm{mg}$, and $10 \mathrm{mg}$ of the NPs (a)

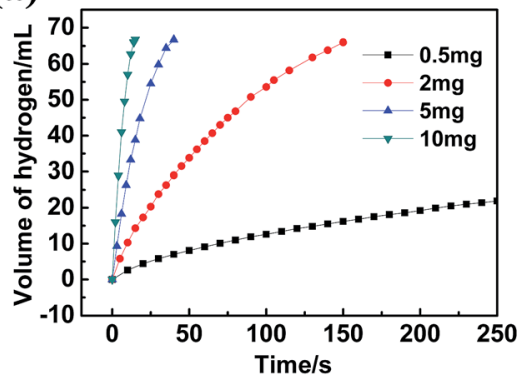

(b)

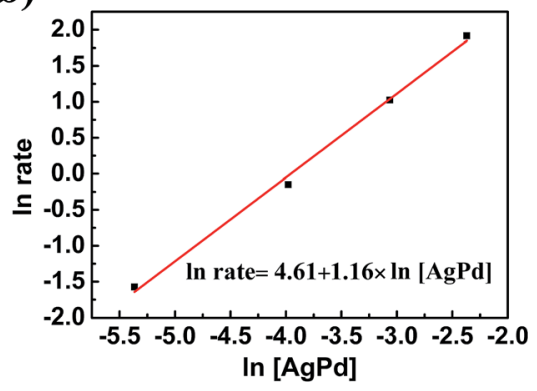

Fig. 6 (a) Plot of reaction time versus volume of hydrogen generated from the methanolysis of $A B$ catalyzed by various dosages of the $\mathrm{Ag}_{30} \mathrm{Pd}_{70} /$ $\mathrm{C}$ catalyst. (b) Plot of the natural logarithm of the hydrogen generation rate versus the natural logarithm of the catalyst concentration (rate $=\mathrm{mL}$ of $\mathrm{H}_{2}$ per $\mathrm{s} ;[\mathrm{AB}]=100 \mathrm{mM}, T=25 \pm 1^{\circ} \mathrm{C}$ ). 
(a)

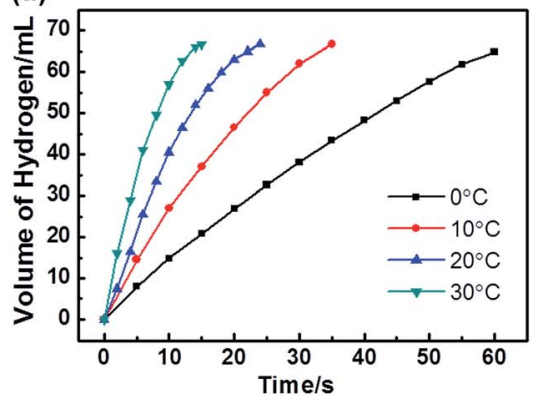

(b)

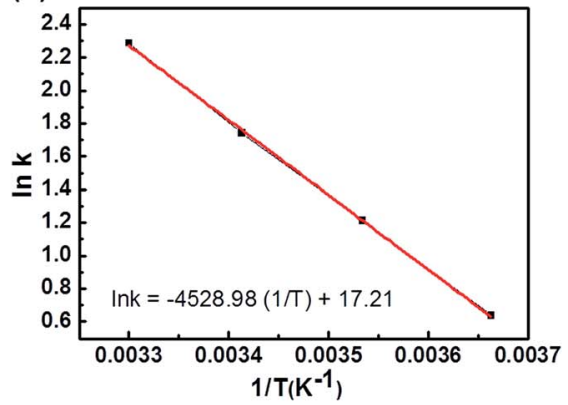

Fig. 7 (a) Plot of reaction time versus volume of hydrogen generated from methanolysis of $A B$ catalyzed by the $A g_{30} P d_{70} / C$ catalyst at various temperatures. (b) Arrhenius plot, i.e., a plot of $\ln k$ versus $1 / T([A B]=100 \mathrm{mM},[\mathrm{AgPd}]=3.2 \mathrm{mM}$ ).

Table 2 Activities of catalysts in the methanolysis of $A B$ at room temperature

\begin{tabular}{|c|c|c|c|}
\hline Catalyst & $\mathrm{TOF} / \mathrm{min}^{-1}$ & $E_{\mathrm{a}} / \mathrm{kJ} \mathrm{mol}^{-1}$ & Ref. \\
\hline $\mathrm{RuCl}_{3}$ & 150 & - & 6 \\
\hline $\mathrm{NiCl}_{2}$ & 2.9 & - & 6 \\
\hline $\mathrm{PdCl}_{2}$ & 1.5 & - & 6 \\
\hline $\mathrm{Cu} @ \mathrm{Cu}_{2} \mathrm{O}$ & 0.16 & - & 12 \\
\hline $\mathrm{Co}-\mathrm{Ni}-\mathrm{B}$ & 10.0 & - & 13 \\
\hline PVP-Pd & 22.3 & $35 \pm 2$ & 33 \\
\hline Rh/zeolite & 30 & 40.04 & 34 \\
\hline $\mathrm{Ru} / \mathrm{MMT}$ & 90.9 & $23.8 \pm 1.2$ & 9 \\
\hline PVP-Ru & 66.95 & $58 \pm 2$ & 35 \\
\hline $\mathrm{CoPd} / \mathrm{C}$ & 27.7 & 25.5 & 15 \\
\hline Mesoporous $\mathrm{Cu}$ & 2.41 & $34.2 \pm 1.2$ & 36 \\
\hline $\mathrm{CuPd} / \mathrm{C}$ & 53.2 & 35.4 & 16 \\
\hline $\mathrm{Cu}-\mathrm{Cu}_{2} \mathrm{O}-\mathrm{CuO} / \mathrm{C}$ & 24 & 67.9 & 14 \\
\hline Ru/graphene & 99.4 & $54.1 \pm 2$ & 11 \\
\hline PVP-Ni & 12.1 & $63 \pm 2$ & 37 \\
\hline $\mathrm{Rh} /$ nano HAP & 147 & $56 \pm 2$ & 38 \\
\hline $\mathrm{Rh} /$ nanosilica & 168 & $49 \pm 2$ & 39 \\
\hline $\mathrm{Ag}_{30} \mathrm{Pd}_{70} / \mathrm{C}$ & 366.4 & 37.5 & This study \\
\hline
\end{tabular}

(representing $\mathrm{Ag}_{30} \mathrm{Pd}_{70}$ concentrations at $0.16 \mathrm{mM}, 0.64 \mathrm{mM}$, $1.6 \mathrm{mM}$, and $3.2 \mathrm{mM}$, respectively), with a constant $\mathrm{AB}$ concentration of $100 \mathrm{mM}$ at $25 \pm 1{ }^{\circ} \mathrm{C}$. The plots of hydrogen generation from the methanolysis of the $\mathrm{AB}$ solution in the presence of different dosages of $\mathrm{Ag}_{30} \mathrm{Pd}_{70} / \mathrm{C}$ NPs are shown in Fig. 6(a). The slope of the linear initial portion of each plot was chosen as the rate of hydrogen generation corresponding to the respective catalyst concentration. As shown in Fig. 6(b), a plot of the natural logarithm of the rate of hydrogen generation versus the natural logarithm of the concentration of $\mathrm{Ag}_{30} \mathrm{Pd}_{70}$ was found to be nearly linear, with a slope of 1.16. The linear nature of this plot indicated that the methanolysis of $\mathrm{AB}$ followed nearly first order kinetics with respect to the concentration of $\mathrm{Ag}_{30} \mathrm{Pd}_{70} / \mathrm{C}$.

To obtain the activation energy of the methanolysis of $\mathrm{AB}$ catalyzed by $\mathrm{AgPd} / \mathrm{C}$ NPs, reactions at various temperatures from $0-30{ }^{\circ} \mathrm{C}$ were carried out. The values of the rate constant $k$ at these temperatures were calculated from the slope of the linear part of each plot shown in Fig. 7(a). The Arrhenius plot, i.e., ln $k v$ s. $1 / T$, for the catalyst is shown in Fig. 7(b), from which the apparent activation energy was determined to be approximately $37.5 \mathrm{~kJ} \mathrm{~mol}^{-1}$. Table 2 summarizes performance features of the various catalysts towards the methanolysis of $\mathrm{AB}$ at room temperature. The $\mathrm{Ag}_{30} \mathrm{Pd}_{70} / \mathrm{C}$ catalyst was determined to be the
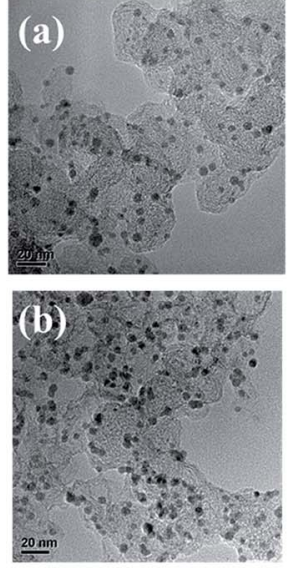

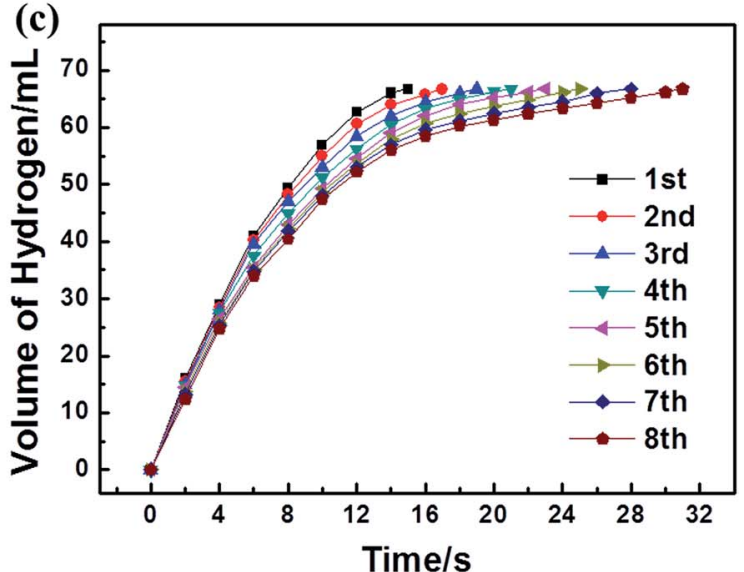

Fig. $8 \mathrm{TEM}$ images of the $\mathrm{Ag}_{30} \mathrm{Pd}_{70} / \mathrm{C}$ catalyst before (a) and after (b) eight catalytic runs. (c) Catalytic performance versus the number of catalytic runs for the $\mathrm{Ag}_{30} \mathrm{Pd}_{70} / \mathrm{C}$ catalyst $([\mathrm{AgPd}]=3.2 \mathrm{mM},[\mathrm{AB}]=100 \mathrm{mM})$. 
most active catalyst, even better than $\mathrm{Ru}^{11}$ - and $\mathrm{Rh}^{38,39}$-based catalysts based on comparing their TOF values.

\subsection{Reusability of the $\mathrm{Ag}_{30} \mathrm{Pd}_{70} / \mathrm{C}$ catalyst}

The reusability of a catalyst is crucial for practical applications. After the first run of methanolysis of $\mathrm{AB}(1 \mathrm{mmol})$ catalyzed by $3.2 \mathrm{mM}$ NPs, the catalyst was kept in the solution and another equivalent amount of $\mathrm{AB}$ was added to the reaction system. The gas generation was monitored and the same procedure was repeated. Fig. 8(c) shows the hydrogen productivity versus reaction time for the generation of hydrogen from the $\mathrm{AB}$ solution catalyzed by $\mathrm{Ag}_{30} \mathrm{Pd}_{70} / \mathrm{C}$ at 8 recycles under ambient conditions. The activity of $\mathrm{Ag}_{30} \mathrm{Pd}_{70} / \mathrm{C}$ catalysts decreased with the number of recycles, and the TOF value dropped from 366.4 to $248.9 \mathrm{~min}^{-1}$ after the eight runs. The TEM images shown in Fig. 8(a) and (b) indicated that there was no noticeable change either in NP size or morphology, so the decreased activity of the $\mathrm{Ag}_{30} \mathrm{Pd}_{70} / \mathrm{C}$ catalysts may be attributed to the loss of metal from the surface of the carbon or the deactivation effect of the increasing metaborate concentration during the methanolysis of $\mathrm{AB}$. To examine this possibility, supernatant liquid after the reusability tests was filtered to remove the support. ICP analysis of the solution indicated the presence of a small amount of Ag.

\section{Conclusions}

In summary, we have reported the synthesis of monodisperse AgPd alloy NPs by the coreduction of silver nitrate and palladium chloride in oleylamine. These NPs exhibited notable activity towards hydrogen generation from the methanolysis of $\mathrm{AB}$ at room temperature due to the uniform size of the particles on the support and the synergistic effects between Ag and Pd. The catalytic activity was found to be closely related to the alloy composition, and the $\mathrm{Ag}_{30} \mathrm{Pd}_{70}$ NPs were shown to be the most active, with a TOF value of $366.4 \mathrm{~min}^{-1}$. The kinetic studies that we carried out on these alloy NPs indicated the catalytic methanolysis of $\mathrm{AB}$ to be first-order with respect to the catalyst concentration. The activation energy was determined to be 37.5 $\mathrm{kJ} \mathrm{mol}^{-1}$. Moreover, the $\mathrm{Ag}_{30} \mathrm{Pd}_{70} / \mathrm{C}$ catalyst retained $67 \%$ of its initial activity after 8 catalytic cycles. Their tunable catalytic properties shown here indicate that these AgPd alloy NPs have great potential in developing $\mathrm{AB}$ as a hydrogen storage material for fuel cell applications.

\section{Acknowledgements}

This work was supported by NSFC project numbers 21476187 and 21536010.

\section{References}

1 L. Schlapbach and A. Züttel, Nature, 2001, 414, 353-358.

2 U. Eberle, M. Felderhoff and F. Schueth, Angew. Chem., Int. Ed., 2009, 48, 6608-6630.

3 J. Yang, A. Sudik, C. Wolverton and D. J. Siegel, Chem. Soc. Rev., 2010, 39, 656-675.
4 T. B. Marder, Angew. Chem., Int. Ed., 2007, 46, 8116-8118.

5 F. H. Stephens, V. Pons and R. T. Baker, Dalton Trans., 2007, 25, 2613-2626.

6 P. V. Ramachandran and P. D. Gagare, Inorg. Chem., 2007, 46, 7810-7817.

7 S. Satyapal, J. Petrovic, C. Read, G. Thomas and G. Ordaz, Catal. Today, 2007, 120, 246-256.

8 M. Diwan, D. Hanna and A. Varma, Int. J. Hydrogen Energy, 2010, 35, 577-584.

9 H. B. Dai, X. D. Kang and P. Wang, Int. J. Hydrogen Energy, 2010, 35, 10317-10323.

10 K. V. Kordesch and G. R. Simader, Chem. Rev., 1995, 95, 191207.

11 S. G. Peng, J. C. Liu, J. Zhang and F. Y. Wang, Int. J. Hydrogen Energy, 2015, 40, 10856-10866.

12 S. B. Kalidindi, U. Sanyal and B. R. Jagirdar, Phys. Chem. Chem. Phys., 2008, 10, 5870-5874.

13 S. B. Kalidindi, A. A. Vernekar and B. R. Jagirdar, Phys. Chem. Chem. Phys., 2009, 11, 770-775.

14 M. Yurderi, A. Bulut, I. E. Ertas, M. Zahmakiran and M. Kaya, Appl. Catal., B, 2015, 165, 169-175.

15 D. H. Sun, V. Mazumder, Ö. Metin and S. H. Sun, ACS Catal., 2012, 2, 1290-1295.

16 P. Y. Li, Z. L. Xiao, Z. Y. Liu, J. L. Huang, Q. B. Li and D. H. Sun, Nanotechnology, 2015, 26, 025401.

17 D. S. Wang and Y. D. Li, Adv. Mater., 2011, 23, 1044-1060.

18 R. G. Chaudhuri and S. Paria, Chem. Rev., 2012, 112, 23732433.

19 M. Zahmakıran and S. Özkar, Nanoscale, 2011, 3, 3462-3481.

20 V. Mazumder, M. F. Chi, M. N. Mankin, Y. Liu, O. Metin, D. H. Sun, K. L. More and S. H. Sun, Nano Lett., 2012, 12, 1102-1106.

21 J. Park, E. Lee, N. M. Hwang, M. Kang, S. C. Kim, Y. Hwang, J. G. Park, H. J. Noh, J. Y. Kim, J. H. Park and T. Hyeon, Angew. Chem., Int. Ed., 2005, 44, 2872-2877.

22 S. Zhang, Ö. Metin, D. Su and S. H. Sun, Angew. Chem., Int. Ed., 2013, 52, 3681-3684.

23 Ö. Metin, S. F. Ho, C. Alp, H. Can, M. N. Mankin, M. S. Gültekin, M. F. Chi and S. H. Sun, Nano Res., 2013, 6, 10-18.

24 Ö. Metin, X. L. Sun and S. H. Sun, Nanoscale, 2013, 5, 910912.

25 D. H. Chen and C. J. Chen, J. Mater. Chem., 2002, 12, 15571562.

26 Y. T. Ji, S. C. Yang, S. W. Guo, X. P. Song, B. J. Ding and Z. M. Yang, Colloids Surf., A, 2010, 372, 204-209.

27 F. F. Lu, D. H. Sun, J. L. Huang, M. M. Du, F. Yang, H. M. Chen, Y. L. Hong and Q. B. Li, ACS Sustainable Chem. Eng., 2014, 2, 1212-1218.

28 E. V. Carino, M. R. Knecht and R. M. Crooks, Langmuir, 2009, 25, 10279-10284.

29 S. W. Han, Y. Kim and K. Kim, J. Colloid Interface Sci., 1998, 208, 272-278.

30 D. S. Lee and Y. W. Chen, J. Taiwan Inst. Chem. Eng., 2013, 44, 40-44. 
31 P. Kamakoti, B. D. Morreale, M. V. Ciocco, B. H. Howard, R. P. Killmeyer, A. V. Cugini and D. S. Sholl, Science, 2005, 307, 569-573.

32 C. Q. Sun, Y. Wang, Y. G. Nie, B. R. Mehta, M. Khanuja, S. M. Shivaprasad, Y. Sun, J. S. Pan, L. K. Pan and Z. Sun, Phys. Chem. Chem. Phys., 2010, 12, 3131-3135.

33 H. Erdogan, Ö. Metin and S. Özkar, Phys. Chem. Chem. Phys., 2009, 11, 10519-10525.

34 S. Caliskan, M. Zahmakiran and S. Özkar, Appl. Catal., B, 2010, 93, 387-394.
35 H. Erdogan, Ö. Metin and S. Özkar, Catal. Today, 2011, 170, 93-98.

36 Q. L. Yao, M. Huang, Z. H. Lu, Y. W. Yang, Y. X. Zhang, X. S. Chen and Z. Yang, Dalton Trans., 2014, 44, 1070-1076. 37 D. Özhava, N. Z. Kılıçaslan and S. Özkar, Appl. Catal., B, 2015, 162, 573-582.

38 D. Özhava and S. Özkar, Int. J. Hydrogen Energy, 2015, 40, 10491-10501.

39 D. Özhava and S. Özkar, Appl. Catal., B, 2016, 181, 716-726. 